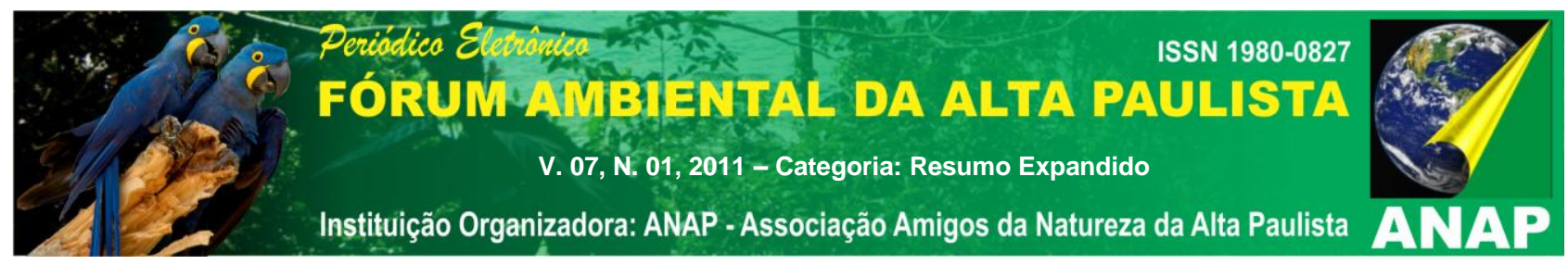

Título do Trabalho

\title{
ESTUdO dA APLICAÇÃO dE PROCESSOS POAS COMBINADOS COMO PRÉ- TRATAMENTO NA DEGRADAÇÃO DE CHORUME
}

Nome do Autor(a) principal

Alessandro Sampaio Cavalcanti

Nome(s) do Co-autor(a) (s)

Mariana Pereira Demarchi Costa, João Victor Serafim Pancotto e Oswaldo Luiz Cobra Guimarães

Nome do Orientador:

Prof. Dr. Hélcio José Izário Filho

Instituição:

Escola de Engenharia de Lorena - Universidade de São Paulo

Instituição de Fomento:

CAPES - Coordenação de Aperfeiçoamento de Pessoal de Nível Superior

E-mail de contato: helcio@dequi.eel.usp.br

Palavras-chave:

Processos Oxidativos Avançados. Fotocatálise. Chorume. Fenton. Dióxido de Titânio.

\section{INTRODUÇÃO}

Em nenhuma fase do desenvolvimento humano se produziu tanto resíduo como atualmente. De acordo com RAMOS (2004), no mundo são gerados cerca de dois milhões 


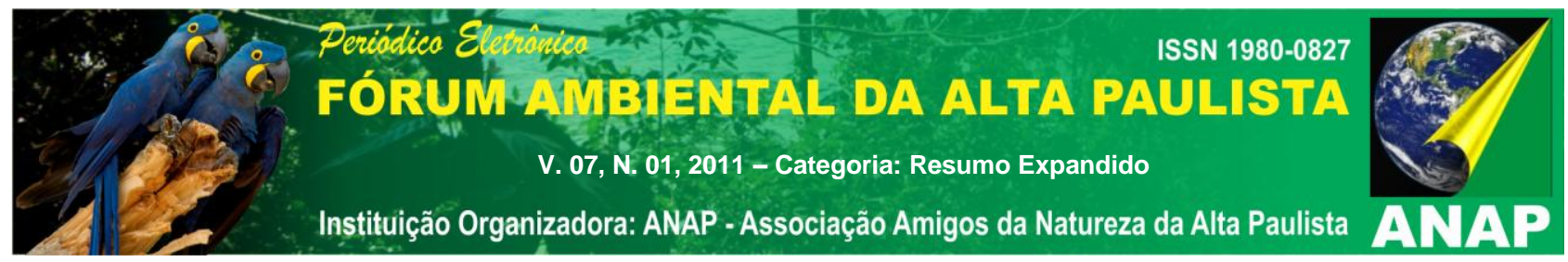

de toneladas de resíduos domiciliar e comercial a cada dia, o que equivale a uma média de aproximadamente $0,7 \mathrm{~kg} \mathrm{dia}^{-1}$ por habitante de área urbana.

Os lixiviados de aterro sanitário podem ser definidos como o efluente líquido originado da umidade natural e da água presente nos resíduos, do resultado da degradação biológica dos materiais orgânicos e da água que infiltra na camada de cobertura e no interior das células existentes no aterro. Este líquido em contato com a água da chuva, percola a massa do aterro, gerando o lixiviado tóxico constituído por água rica em sais, metais pesados e matéria orgânica (MORAVIA, 2007).

O tipo de resíduo disposto no aterro, o grau de decomposição, o clima, a idade e a profundidade do aterro, o tipo de operação aplicada no aterro, entre outros, dão origem às características químicas, físicas e biológicas do lixiviado. Assim, a sua composição pode variar de um local para outro ou em um mesmo local em épocas do ano diferentes (TELLES, 2010).

O chorume em sua maioria possui pouca biodegradabilidade e não se consegue remediá-lo adequadamente apenas por processos biológicos. Em conseqüência desses fatores, torna-se absolutamente essencial a busca de novas alternativas para 0 tratamento desta matriz. Os Processos Oxidativos Avançados (POAs) têm sido empregados com excelentes resultados nas substâncias orgânicas recalcitrantes (KOCHANY \& LIPCZVNSKA-KOCHANY, 2009).

A fotocatálise pode apresentar importante papel com relação às tecnologias emergentes para o tratamento de lixiviados, bem como o potencial para o aproveitamento energético sustentável que o Brasil possui, principalmente no que diz respeito ao uso de energia solar como fonte de energia alternativa (DOMÈNECH et al, 2001).

A fotocatálise homogênea utiliza a luz solar combinada com os reagentes Fenton $\left(\mathrm{H}_{2} \mathrm{O}_{2} / \mathrm{Fe}^{2+}\right)$ fornecendo através da reação complexa de íons ferro em meio ácido, radicais hidroxila $(\cdot \mathrm{OH})$, com baixo custo na remoção de substâncias recalcitrantes do chorume, já que a luz solar é abundante no Brasil e com baixo custo dos reagentes Fenton (HERMOSILLA, 2009).

A utilização da fotocatálise heterogênea vem sendo apontada como uma das formas mais promissoras no tratamento de resíduos recalcitrantes. Trata-se de um processo fotoquímico em que uma espécie semicondutora como Dióxido de Titânio $\left(\mathrm{TiO}_{2}\right)$ 


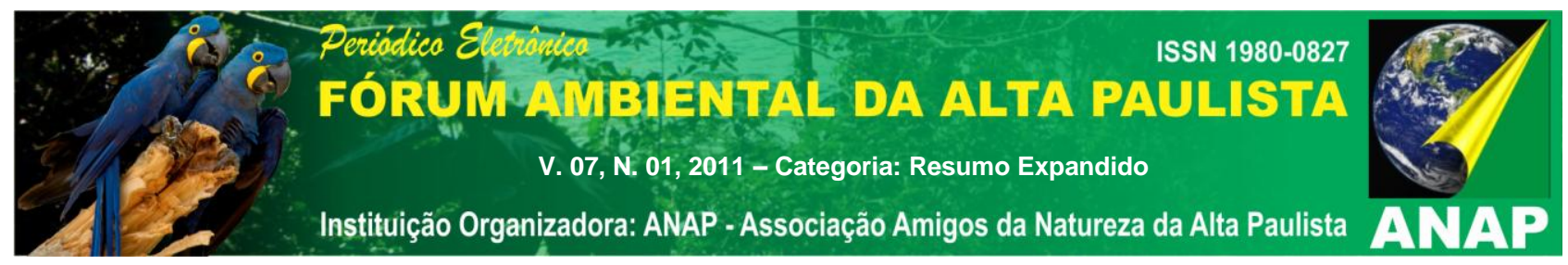

é irradiada para a promoção de um elétron da banda de valência para a banda de condução (FREIRE et al., 2000).

\section{OBJETIVO GERAL}

Este trabalho tem como objetivo o estudo do processo oxidativo avançado (POA), especificamente os efeitos da fotocatálise homogênea (foto-Fenton Solar) e heterogênea $\left(\mathrm{TiO}_{2}+\right.$ UV solar) no processo para a degradação dos constituintes orgânicos do chorume da cidade de Cachoeira Paulista-SP, a fim de que o mesmo, após o tratamento, atenda as características dos parâmetros físicos e químicos da legislação para descarte em corpos receptores (rios).

\section{OBJETIVOS ESPECÍFICOS}

Realizaram-se 18 experimentos para verificar a sinergia entre os fatores placa de $\mathrm{TiO}_{2}$, o reagente Fenton e $\mathrm{opH}$ na degradação da carga orgânica do chorume, tendo como variável resposta a redução percentual de COT.

Verificou-se a melhor condição experimental e as significâncias dos fatores analisados através de ferramentas estatísticas, buscando avaliar os efeitos individuais de cada fator e o sinergismo entre os POAS para a redução da Carga Orgânica do chorume utilizando a variável resposta COT.

\section{MATERIAS E MÉTODOS}

Para este estudo foi utilizado chorume fornecido pela empresa VSA-Vale Soluções Ambientais do aterro sanitário da cidade de Cachoeira Paulista-SP. Os experimentos e as análises físico-químicas foram realizadas nos laboratórios LOB (Departamento Básico e Ciências Ambientais) e LOQ (Departamento de Engenharia Química) da Escola de Engenharia de Lorena (EEL-USP).

Para a caracterização analítica deste estudo, metodologias padrões já estabelecidas (USEPA, Standard Methods, CETESB, APHA-AWWA) foram empregadas, 


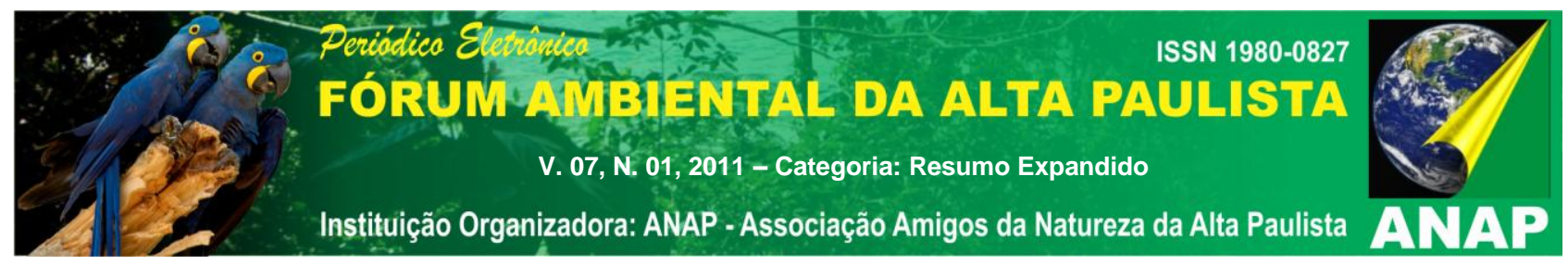

sendo determinados a COT, DQO e DBO, e espécies inorgânicas como fósforo total, nitrogênio, $\mathrm{Cr}$, $\mathrm{Fe}$, entre outros inorgânicos, estes feitas por espectrometria de absorção atômica com atomização por chama e forno de grafite e por espectrofotometria UVVisível.

Os 18 experimentos foram realizados em um "reator" batelada aberto para a absorção das radiações UV solar, constituído basicamente de uma bomba centrífuga (BOMAX, Modelo NH-30PX-T e vazão de $13 \mathrm{~L} / \mathrm{min}$ ), um reservatório cilíndrico (19,9 cm X $23,9 \mathrm{~cm}$ ) e duas placas metálicas ( $25 \mathrm{~cm}$ de largura e $75 \mathrm{~cm}$ de comprimento, com uma área útil de $\left.1875 \mathrm{~cm}^{2}\right)$, uma revestida com tinta de elevada concentração de $\mathrm{TiO}_{2}(0,025$ $\mathrm{g} / \mathrm{cm}^{2}$ ) e a outra sem pigmentação denominada branco. $\mathrm{O}$ controle e ajuste do $\mathrm{pH}$ durante os experimentos foram adaptados ao reservatório um pHmetro ( $\mathrm{PH} 21 \mathrm{pH} / \mathrm{mV}$ HANNA) e a intensidade da radiação solar foi medida através de um radiômetro portátil (IL 1430 UV Health Hazard - Actinic). No sistema de tratamento, o chorume foi bombeado até a parte superior da placa, percolando-a uniformemente enquanto recebia a radiação solar sobre a placa. Esta foi colocada sobre um suporte de madeira em sentido ao equador com um ângulo de inclinação de $23^{\circ}$ (aproveitamento melhor da incidência da radiação na fotocatálise). Após o ajuste das condições do chorume, de acordo com a planilha experimental, os reagentes Fenton $\left(\mathrm{H}_{2} \mathrm{O}_{2}+\mathrm{Fe}^{2+}\right)$ foram adicionados concomitantemente no início da reação, com vazão controlada durante 60 min.

Os níveis das variáveis de entrada do processo foram: $\mathrm{pH}\left(3,8\right.$ e 11), placa $\left(\mathrm{TiO}_{2}\right.$ e branco) e relação mássica de Peróxido de Hidrogênio e ĺon Ferroso (228, 381 e 1140), sendo o tempo de reação para todos os experimentos de 120 minutos e a variável resposta foi a redução percentual de COT. As análises estatísticas foram realizadas pelo software Minitab 15.0.

\section{RESULTADOS}

O chorume tratado possui características recalcitrantes e poluentes devido a sua baixa relação de biodegradabilidade $(\mathrm{DBO} / \mathrm{DQO}=0,15)$ e altas concentrações de $\mathrm{DQO}$ (2700 $\left.\mathrm{mg} \mathrm{O}_{2} / \mathrm{L}\right)$, DBO (412 $\left.\mathrm{mg} \mathrm{O}_{2} / \mathrm{L}\right)$ e COT $(856 \mathrm{mg} \mathrm{C} / \mathrm{L}$ ), e adversas características físicas como a turbidez (630 NTU) e Cor (1763 Pt-Co / mg/L). 


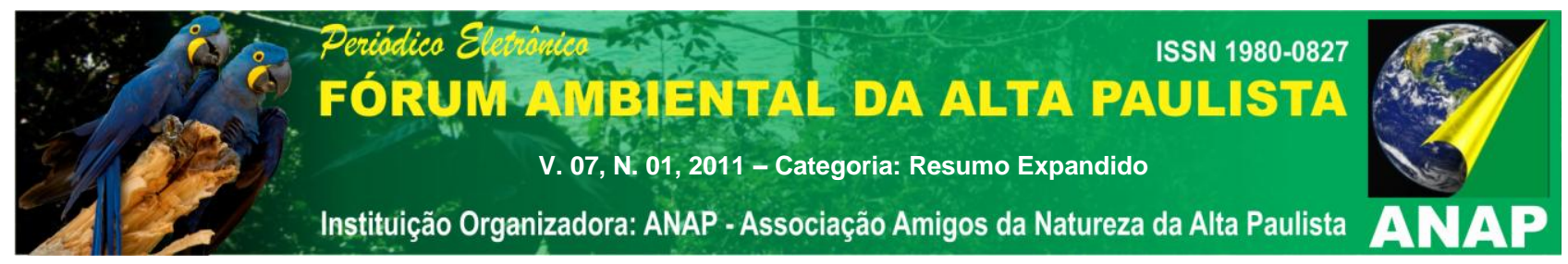

Através dos experimentos e análises estatísticas do processo, a média de remoção dos 18 experimentos foi de 16,8 \% COT e desvio médio de 8,31\%, obtidos através do teste de Kolmogorov-Sirnov (KS), no qual, para p-valor $>0,15$ indica que a distribuição dos dados segue a normalidade. Confirmados através da análise de variância e resíduos, onde o processo mostrou excelente confiabilidade $\left(R^{2}=99,78 \%\right.$ e $\left.R=96,19 \%\right)$.

$A$ análise de efeitos (teste $p<0,05$ ) dos fatores mostrou concomitantemente com análise de resíduos que $\mathrm{opH}$ foi fator mais significante, tendo melhor desempenho no processo no nível $\mathrm{pH}(3,0)$ e os outros fatores e interações obtiveram baixa significância, a placa branco obteve melhor desempenho em relação a placa de $\mathrm{TiO}_{2}$ e a relação mássica obteve melhores nos níveis 228 e 381 . A melhor condição experimental nesse estudo foi a utilização da placa branco, em pH 3,0, e a relação mássica nos níveis 228 e 381 , alcançando a remoção de 32,1 \% de COT e 48,8 \% DQO. Desta forma, não houve sinergismo entre as fotocatálises, mostrando que a oxidação por foto-Fenton foi a mais significativa, em função ao porcentual de redução do COT. Com o mesmo tipo de efluente, no trabalho de DENG (2006), o processo Fenton obteve os melhores resultados em pH 3,0 e relação mássica $\mathrm{H}_{2} \mathrm{O}_{2} / \mathrm{Fe}^{2+}$ de 2,5, e no trabalho de VILAR (2011), o processo foto-Fenton com placa branco (sem pigmentação) obteve melhores resultados em relação a placa de $\mathrm{TiO}_{2}$.

\section{CONSIDERAÇÕES FINAIS}

Verificou-se que os catalisadores $\mathrm{TiO}_{2}$ e 0 ín Ferroso $\left(\mathrm{Fe}^{2+}\right)$ não obtiveram resultados expressivos trabalhando concomitantemente na degradação do chorume, apresentando antagonismo entre eles, isto, provavelmente, em função do pH. O melhor resultado dos experimentos obteve um resultado expressivo na remoção da carga orgânica, mas ainda não pode ser descartado no corpo receptor, necessitando, assim, mais experimentos com os fatores mais significativos e otimização dos respectivos níveis para atingir os limites estabelecidos pela legislação.

\section{REFERÊNCIAS}




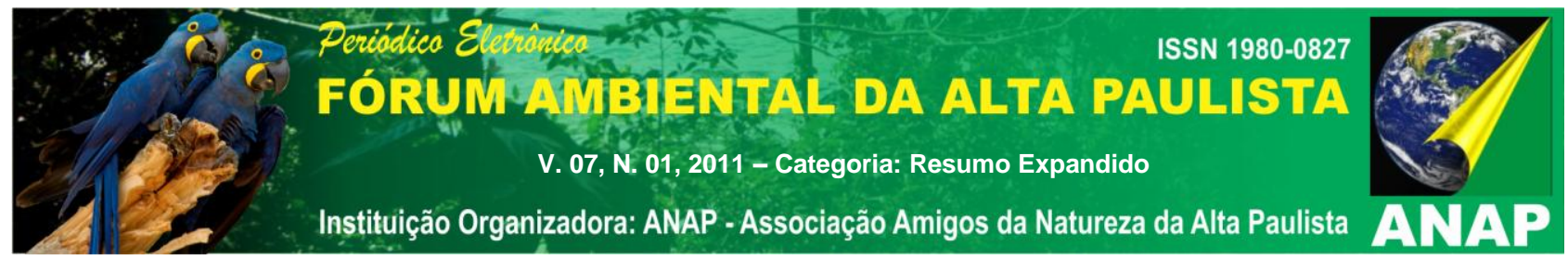

APHA-AWWA. Standart methods for examination of water and wastewater. Washington: American Public Health Association - American Water works association, 1998.

DENG,Y.;Englehardt,A. Treatment of landfill leachate by Fenton process - a review, Water Research.40, 2006, p. 3683-3694.

Domènech, X.; Jardim, W. F.; Litter, M. I. Procesos avanzados de oxidación para la eliminación de contaminantes. In: ELIMINIACIÓN de Contaminantes por Fotocatálisis Heterogênea. La Plata: Rede CYTED, 2001. Cap. 1.

FREIRE, R. S.; PELEGRINI, R.; KUTOTA, L. T; DURAN, N.; PERALTA-ZAMORA, P.; Novas Tendências para o Tratamento de Resíduos Industriais contendo Espécies Organocloradas. Quimica Nova, 23(4), 2000, p. 504-511.

HERMOSILLA, D.; CORTIJO,M.; HUANG, C.P. Optimizing the treatment of landfill leachate by conventional Fenton and Photo-Fenton processes, Science of the total environment, 2009, p. 3470-3473.

LIPCSYNSKA-KOCHANY E and KOCHANY J Humic substances in bioremediation of industrial wastewater - Mitigation of inhibition of activated sludge caused by phenol and formaldehyde. J. Environ. Sci. Health A 43, 2009, p. 619-626.

MORAVIA, WAGNER GUADAGNIN. Estudos de caracterização, Tratabilidade e Condicionamento de Lixiviados visando Tratamento por Lagoas. Belo Horizonte. p.17-21, 2007.

RAMOS, S. I. P, Sistematização técnico-organizacional de programas de gerenciamento integrado de resíduos sólidos urbanos em municípios do estado do Paraná. Dissertação (Mestrado em Engenharia Química) - Universidade Federal do Paraná - UFPR, Curitiba, 2004, p 11-12.

TELLES,C.A.S. Processos Combinados para o Tratamento de Lixiviado de Aterro Sanitário.Dissertação (Mestrado em Engenharia Química) - Universidade do Rio de Janeiro - UFRJ, Rio de Janeiro, 2010, p. 22-23.

VILAR, J.P.V.; MOREIRA J.M.S.; BOAVENTURA RAR.; Solar photo-Fenton as a préoxidation step for biological treatment of landfill leachate in a plot with CPCs Journal of Hazardous Materials, 2011, p. 228-234. 